J. Asiat. Soc. Bangladesh, Sci. 38(2): 175-181, December 2012

\title{
STATUS AND DISTRIBUTION OF RHESUS MACAQUE, MACACA MULATTA IN METROPOLITAN DHAKA CITY
}

\author{
RUKSHANA SULTANA \\ Herpetologist, Bangladesh Forest Department, Ministry of Environment and Forest (MoEF) \\ Ban Bhaban, Sher-E-Bangla Nagar, Agargaon, Dhaka
}

\begin{abstract}
A field study was conducted on the status and distribution of the population of rhesus macaque, Macaca mulatta (monkeys) between June 2005 to September 2005. The population survey was made in 10 study sites of old Dhaka city employing transect census technique. I found a total of 178 rhesus macaques ranging in 10 individual troops in old part of Dhaka city. A good number of rhesus population was noted in three places, among them the highest population was seen in Shadhana Awshadhalaya Factory area (59 individuals) and the lowest was (4 individuals) in Radhika Mohan Bosak lane. Population study of rhesus macaques and investigation of their distribution is extremely important as they become part of the ecosystem of those areas. Hence, appropriate conservation measures should be taken to protect the monkeys.
\end{abstract}

Key words: Population, Distribution, Macaca mulatta, Urban, Dhaka

\section{Introduction}

After receiving the status of capital city, urbanisation has geared up in Dhaka city. This might be responsible in rapid loss of vegetations in and around the city. But surprisingly with increased urbanisation a good number of rhesus macaque has been living as commensal animal with human. Although this kind of commensalism has been seen in various temples of India where people have considered rhesus macaques as one of their Gods' (Pirta et al. 1997 and Jolly 1985). However, the scenario is different in metropolitan Dhaka because Bangladesh is primarily an Islamic nation and also after partition in 1947 and the liberation war in 1971, decrease of a large number of Hindu population has significantly jeopardised the population of urban rhesus monkey (Green 1978 and Oppenheimer et al. 1983). Feeroz et al. (1995) mentioned that primate research has started in our country in 1976 and was first conducted by Akonda in 1976. After that only few studies have been conducted to find out the status and distribution of rhesus macaque's population in Dhaka city (Oppenheimer et al. 1983 and Feeroz et al. 1995). Mention worthy, Feeroz et al. (1995) focused on locating non-human primate's species around the country. However, no population census was conducted before in Dhaka. I warranted this long gap in the trend of urban rhesus macaque population study. Therefore, I conducted a population survey of rhesus macaque in order to determine its status and distribution. 


\section{Materials and Methods}

Transect census technique was applied to conduct the population survey of rhesus monkeys. The whole area of the old Dhaka city was divided into four parts and each part was further divided into 3 to 4 sections based on location and established roadways. After reaching an area a transect line was selected randomly, usually pathways and roadways. When monkeys were seen, observer recorded the time of the sighting, path and height of first sighting, group size and behaviour. Observer also identified age and sex of individual monkey. Census was conducted mostly in the early morning at 0600 hours and mid- to late afternoon at 1800 hours. The census was conducted mostly on foot along the established road sides. In addition to minimize the possibility of observer bias, I spent similar amounts of time working on each transect and made repeated counts. The monkeys were searched for and resident people were interviewed for detail information. In this way the location of the monkeys were noted and number of troops were counted. I also used puffed rice, biscuits and bread to attract troop members to climb down from the roofs. Current study was performed from June 2005 to September 2005.

During survey attempts were made to find as many rhesus troops as possible to obtain an age-sex count in each group every time. Generally, monkeys were observed largely in the morning and in the late evening when most of the individuals of a group stayed together. A binocular was used to determine their sex and age.

Individuals were classified as adult males, adult females, juveniles and infants according to the modified criteria of Stanford (1991) and Southwick et al. (1961a and $1961 \mathrm{~b}$ ).

Study site : The study was conducted in the urban area of Dhaka city where rhesus monkeys live close to human habitation. According to Dhaka Statistical Metropolitan Area (DSMA) the total area of Dhaka is 797 square kilometer (Islam 2005) which is situated between $23^{\circ} 42^{\prime}$ and $23^{\circ} 54^{\prime} \mathrm{N}$ latitudes and $90^{\circ} 20^{\prime}$ and $90^{\circ} 28^{\prime} \mathrm{E}$ longitudes. The city is bounded by the river Buriganga on south, by Tongi on the north, Demra and Narayangang on the east, and by Savar on the west (Banglapedia 2004).

Dhaka city can be conveniently divided into two parts- the old Dhaka and the new Dhaka. The old part includes Postogola, Gandaria, Sutrapur, Narinda, Nawabgang, Armanitola, Tanti Bazar, Sadarghat, Nawabpur, Bangsal, Banagram, Shankhari Bazar, Wari etc. having an area of approximately 5 square kilometer and the remaining areas can be included in new Dhaka. Most of the rhesus monkeys live in the old part of the city but the author found few troops of rhesus monkeys to travel in some places of new Dhaka like Gopibag, Lalmatia and Tejgaon old airport area and Dhaka Cantonment area.

The buildings in the old Dhaka are very close to each other situated with little or no space from one another. The buildings are also old; some collapsed during the study period and some buildings has been broken down for reconstruction. The buildings and roads are narrow and congested. In the new Dhaka area unlike the old Dhaka, there are spaces 
between the buildings. Construction of infrastructures like, roads and buildings are done by planned way leaving much space between two buildings as well as the roads are comparatively wide.

The author had visited following areas to locate the presence and abundance of monkeys. The study area includes Shadhana Awshadalaya factory, Gandaria, Wari, Banagram, Shutrapur, Narinda, Bangshal, Suritola, Guriatuli, Golnagar, Shankhari bazaar, Gopibag, Uttar Musondi, Rhadika Mohon Bosak Lane, Tejgaon Old Airport Area, and Lalmatia (Fig. 1).

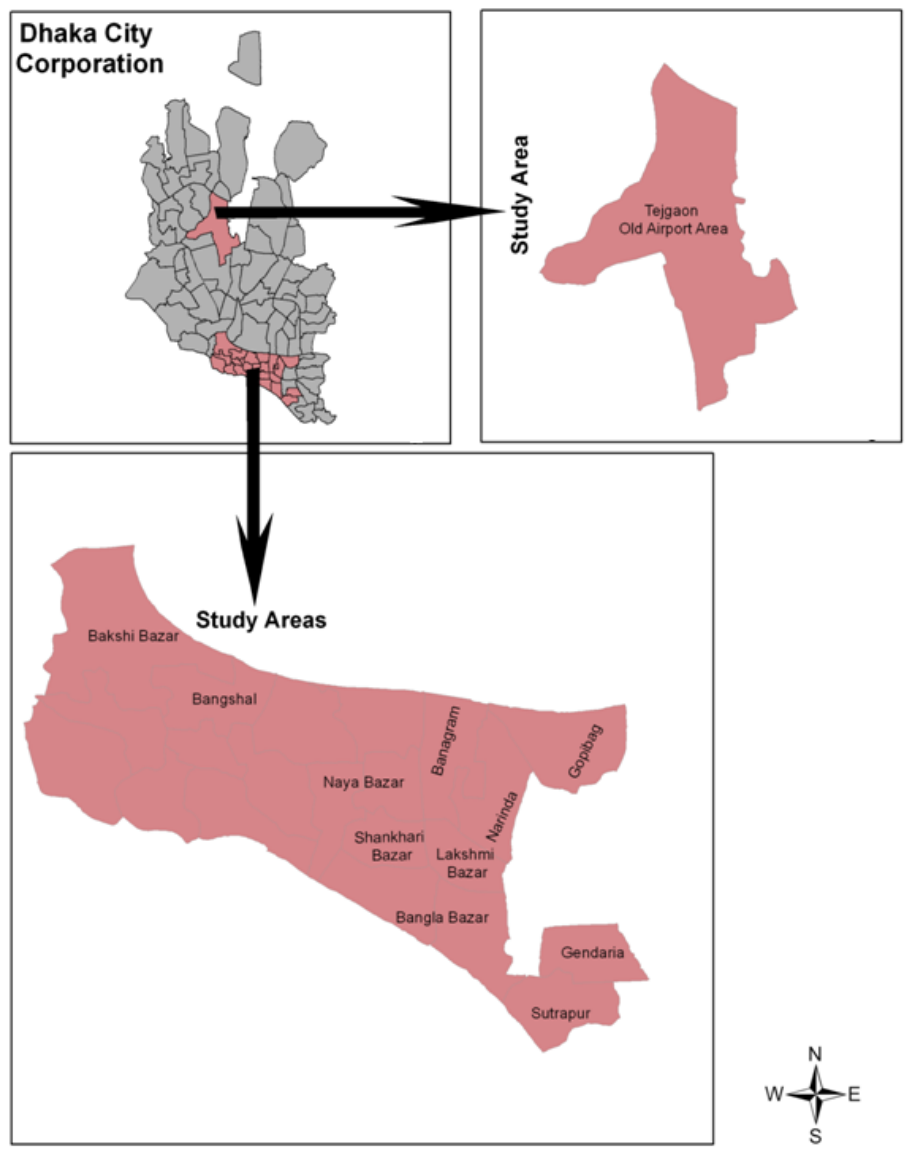

Fig. 1. Map of Dhaka City Corporation and study areas.

\section{Results and Discussion}

In this survey, a total 10 groups with a total of 178 monkeys were found. Among the population, individuals were 36 adult males (20.23\%), 93 adult females $(52.25 \%), 32$ 
juveniles (17.98\%) and 17 infants (9.55\%) (Table 1 and Fig. 2). All the groups were bisexual containing both the male and the female members.

Table 1. Group sizes of rhesus monkeys of Dhaka city (June to September 2005).

\begin{tabular}{cccccc}
\hline Location & Adult male & $\begin{array}{c}\text { Adult } \\
\text { female }\end{array}$ & Juvenile & Infant & Total \\
\hline $\begin{array}{c}\text { Shadhana } \\
\text { Awshadhalaya } \\
\text { Factory }\end{array}$ & 6 & 31 & 13 & 9 & $\mathbf{5 9}$ \\
$\begin{array}{c}\text { Suritola / Taker Hatt } \\
\text { Guriatuli / }\end{array}$ & 2 & 11 & 5 & 1 & $\mathbf{1 9}$ \\
Mohajonpur lane & 7 & 13 & 5 & 2 & $\mathbf{2 7}$ \\
$\begin{array}{c}\text { Banagram / } \\
\text { Shosimohan Bosac } \\
\text { lane }\end{array}$ & 4 & 5 & 2 & 2 & 13 \\
$\begin{array}{c}\text { Wari / Joginagar } \\
\text { Goalnagar }\end{array}$ & 3 & 5 & 0 & 1 & 9 \\
$\begin{array}{c}\text { Shankhari Bazar / } \\
\text { Tanti Bazar }\end{array}$ & 5 & 4 & 1 & 0 & 6 \\
Utter Musondi & 4 & 9 & 1 & 2 & 17 \\
$\begin{array}{c}\text { Radhika Mohan } \\
\text { Bosak lane / Gulon } \\
\text { Bari / Razar Deuri }\end{array}$ & 1 & 6 & 2 & 0 & 12 \\
$\begin{array}{c}\text { Tejgaon old airport } \\
\text { area }\end{array}$ & 3 & 2 & 1 & 0 & 12 \\
\hline Total & $\mathbf{3 6}$ & $\mathbf{9 3}$ & $\mathbf{3 2}$ & $\mathbf{1 7}$ & \\
\hline
\end{tabular}

Akonda (1976) had found 11 troops of rhesus macaques consisting of 196 individuals in March, 1976 which increased into 220 individuals after a birth season in September of the same year. In the same year in another study, Oppenheimer et al. (1983) reported that there were 11 troops located in the old Dhaka city and total count of population was 229 comprised of 22 adult males, 83 adult females, 82 Juveniles and 49 infants in September 1983. After that there was a long gap in the study of urban rhesus macaque which was partially filled when Feeroz et al. (1995) recorded 11 troops in Dhaka city with a total population of 196 individuals. These studies have shown the declining trend of urban rhesus macaque population in Dhaka city. 


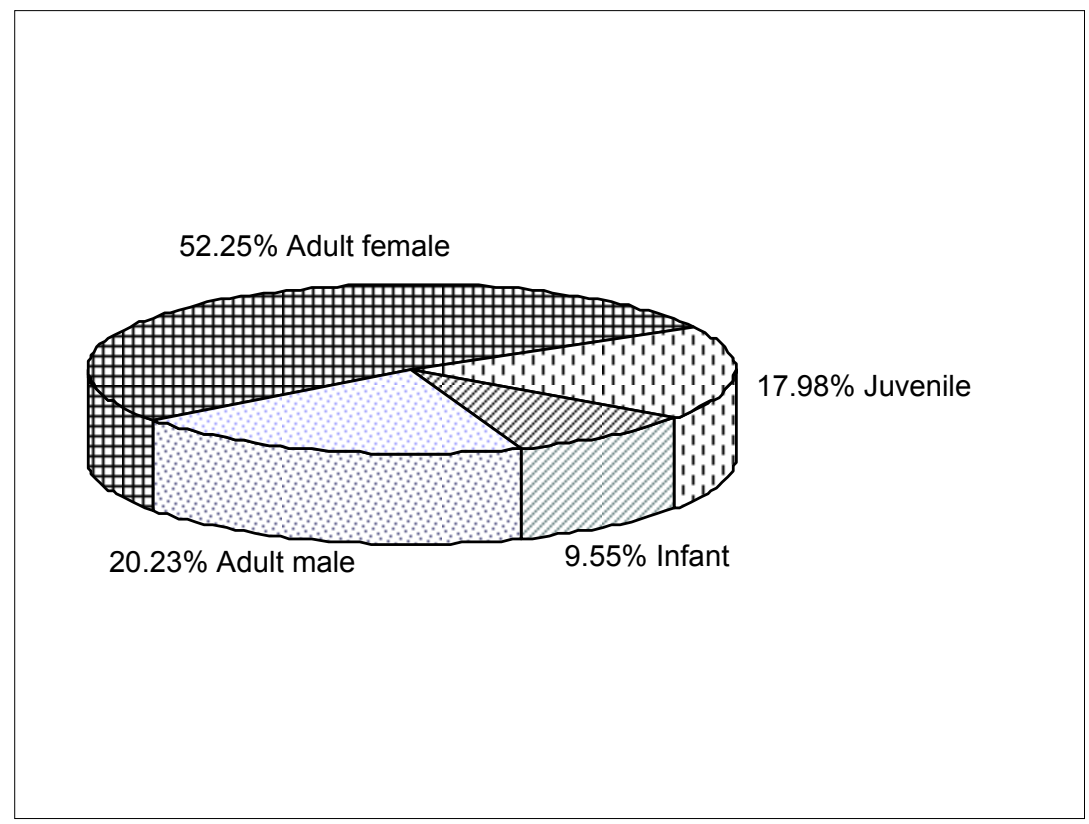

Fig. 2. Age-sex composition of rhesus macaques in Dhaka city.

The comparative study shows that number of adult male and female has increased but a declining trend is visible in terms of juvenile and infant number. Oppenheimer et al. (1983) reported that much of the infant loss in Dhaka occurred from the contact with electric wares, attacks by people and possibly due to diseases. Present study suggests that habitat destruction, increasing human population size (Oppenheimer et al. 1983), continuous human harassment (Feeroz et al. 1995 and Oppenheimer et al. 1983), felling of fruit trees and presence of high rise buildings could be the physical reasons to justify their population decline.

Oppenheimer et al. (1983) mentioned that out of 14 troops, three areas were nonaccessible. These were the Cantonment which was confined to military, Bangabhaban which is the residential compound of the President of the Bangladesh and Hari Charan Roy where troop was removed by the Dhaka Zoo staffs. During study period I found no rhesus in Bangabhaban and Feeroz et al. (1995) also did not mention of the existence of any rhesus monkeys in these areas. However, I studied Tejgaon old airport area adjacent to the Cantonment area where, I have found a total of 12 rhesus macaques with 3 adult males, 7 adult females and 2 infants (Table 1).

The rhesus population was greater in three places, Shadhana Awshadhalaya Factory (SAF), Guriatuli and Suritola of the old Dhaka city than the other places I studied. The 
highest population were 59 macaques found in SAF area (10.16\% adult male, $52.54 \%$ adult female, $22.03 \%$ juvenile and $15.25 \%$ infant) followed by 29 and 19 monkeys in Guriatola and Suritola, respectively. Oppenheimer et al. (1983) recorded only a total of 18 populations in SAF area which was the third highest population of the all recorded population. The highest population recorded by Oppenheimer et al. (1983) was in Tanti Bazar area with a total of 36 populations which decreased to 17 individuals as I recorded during my study.

The smallest troop was found at Radhika Mohan Bosak lane area consisting of 4 individuals recorded during the population study period in 2005 . The lowest population (3 individuals of 1 adult male, 1 adult female and 1 juvenile) was recorded by Oppenheimer et al. (1983) in Railway staff colony which was not mentioned by Feeroz et al. (1995). Even I also have not found any individual there. It means that we have lost the population already.

It is noticeable that in every population, the number of the female was higher than their male counterpart. The total number of the females and the males was 93 and 36, respectively (Table 1). This number depicts that the average sex ratio was 2 .

Though rhesus macaque population has lost some of their habitats and their fate is still uncertain but considering the above population size it can be said that the population has increased in Shadhana Awshadhalaya Factory. The possible reason could be because the factory people fed them and offer shelter to these rhesus macaques.

Rhesus monkeys have been living in Dhaka city for a long time. Early records showed that a considerable number of monkeys were living at the outskirts of Dhaka city (Husain 1974). The fundamental season behind the presence of rhesus monkeys' in Dhaka city is still unknown. Though Oppenheimer et al. (1983) suggested that prior to urbanisation the land was used for agricultural purpose and later urbanisation started in Dhaka city with the migration of Hindu population in 1948. It is said that as a large number of Hindu population reside there and monkey is an object of their worship, so they might bring it with them. But the scientists authorized the fact that in ancient time Dhaka city was densely covered by forest, where an enormous population of rhesus macaques were resided, which was destroyed and later altered by land clearing for agricultural purpose (Johnson 1975). Though the city expanded largely with time but the macaques remain here as it has high tolerance to the adverse condition.

However, effective management planning to conserve the urban rhesus macaques' population is yet far cry. Feeroz et al. (1995) noted that perspective in primate conservation is a challenging issue where most countrymen fail to fulfil basic needs only. But a ray of light of hope has fallen into this misery of primate conservation when rhesus macaque has been listed in the Schedule I as a protected animal in new Wildlife (Conservation and Security) Act, 2012. 


\section{References}

Akonda, A.W. 1976. Study of population and activity patterns of Rhesus monkey Macaca mulatta zimmer mann, M. Sc. Thesis (Unpublished). University of Dhaka, Bangladesh.

BANGLAPEDIA, February, 2004. Multimedia CD Addition. Asiatic Society of Bangladesh, Dhaka.

Feeroz, M.M., M. A. Islam and M. Kabir, 1995. Status distribution and conservation of primates of Bangladesh. Kyoto University Overseas Research Report of Studies on Asian Non-human Primates. 9 : 73-82.

Green, K. M. 1978. Primates of Bangladesh: A preliminary survey of population and habitat. Biol. Conserv. 13 : 141-160.

Husain, K.Z. 1974. An introduction to the wildlife of Bangladesh. F. Ahmed. Dhaka.

Islam, N. 2005. Dhaka now- contemporary urban development. Bangladesh Geographical Society (BGS). 9-20

Johnson, B. L. C. 1975. Bangladesh. New York, Barnes and Noble.

Jolly, A. 1985. The evolution of primate behaviour. $2^{\text {nd }}$ edition. Macmillan, New York.

Oppenheimer, J. R., A. W. Akonda and K. Z. Husain, 1983. Rhesus monkeys: Effect of habitat structure, human contact and religious beliefs on population size. Perspective in Primate Biology. 193-199 pp.

Pirta, R. S., M. Gadgil and A. V. Kharshikar, 1997. Management of the rhesus monkey Macaca mulatta and human langur Presbytis entellus in Himachal Pradesh, India. Biological Conservation. 79 : 97-106

Stanford, C. B. 1991. The capped langur in Bangladesh; behavioral ecology and reproductive tactics. Contributes to Primatology. $26: 1-179$

Southwick, C.H., M. A Beg and M.R. Siddiqi, 1961a. A population survey of rhesus monkeys in villages, towns and temples of northern India. Ecology. 42 : 538-547.

Southwick, C.H., M., Beg and M. R. Siddiqi, 1961b. A population survey of rhesus monkeys in India: II transportation routes and forest areas. Ecology. $42: 698-710$

(Received revised manuscript on 3.11.12) 